\title{
A PRÁTICA DA GOVERNANÇA CORPORATIVA E SUA INFLUÊNCIA PARA OS STAKEHOLDERS ENVOLVIDOS NO DESENVOLVIMENTO DE UM PROJETO ESPORTIVO DO SESI-SP
}

\author{
${ }^{1}$ Felipe de Pilla Varotti \\ ${ }^{2}$ João Manuel Malaia
}

\section{RESUMO}

O SESI-SP, entidade sem fins lucrativos, firmou parceria com o British Council e Premiership Rugby para desenvolver o projeto esportivo TRY Rugby-SP. Essas entidades internacionais, impulsionadas pelo cenário favorável ao crescimento do rúgbi no Brasil, procuravam uma organização esportiva que possuísse uma estrutura de gestão semelhante a que utilizam. Visualizaram no SESI-SP os princípios de Governança Corporativa. Por meio de uma pesquisa qualitativa e exploratória, utilizando-se de um estudo de caso, analisamos como a Transparência, Equidade, Prestação de Contas e Responsabilidade Corporativa, ou seja, boas práticas de Governança Corporativa, foram utilizadas para desenvolvimento do projeto esportivo TRY Rugby-SP. Verificamos também como a Governança Corporativa influenciou os principais stakeholders - British Council e Premiership Rugby - e os motivos que os levaram a ter credibilidade no SESI-SP para que aportassem recursos neste projeto. Os dados foram coletados utilizando a triangulação com as seguintes ferramentas: Observação e participação direta de um dos pesquisadores, Análise de Documentos e Entrevistas. Os sujeitos deste estudo foram os stakeholders principais envolvidos, somente aqueles que aportaram recursos financeiros para a execução do projeto. O sistema de gestão e as boas práticas de Governança Corporativa do SESI-SP foram fundamentais para atrair o interesse de stakeholders. Assim, contribuímos para que organizações esportivas compreendam e passem a adotar as boas práticas da Governança Corporativa, valorizando a sua imagem institucional perante os seus possíveis stakeholders e atraindo maiores investimentos para execução de seus projetos.

Palavras chave: Governança Corporativa, Governança Corporativa no Esporte, Stakeholders.

\footnotetext{
${ }^{1}$ Mestrando em Administração pela Universidade Nove de Julho, São Paulo - UNINOVE, Brasil.

E-mail: felipevarotti@hotmail.com

2 Doutor em História Econômica pela Universidade de São Paulo - USP, Brasil.

Professor do Programa de Mestrado Profissional em Gestão do Esporte da Universidade Nove de Julho, São Paulo - UNINOVE, Brasil.

E-mail: jmalaia@gmail.com
} 


\title{
THE PRACTICE OF CORPORATE GOVERNANCE AND ITS INFLUENCE TO STAKEHOLDERS INVOLVED IN THE DEVELOPMENT OF A SPORTING PROJECT OF SESI-SP
}

\begin{abstract}
Sesi-SP, a nonprofit entity, in partnership with British Cuncil and Premiership Rugby are developing a sporting project named Try Rugby-SP. These internacional entities, driven by a favorable scenario supporting the continuous growth of rugby in Brazil, were looking a sport organization with a similar management structure adopted by them. In this sense, SESI-SP was selected due the Principles of Corporate Governance. Indeed, we applied qualitative and exploratory research to a case study. In this work, we analysed how good corporate governance practices like Transparency, Equity, Accountability and Corporate Responsibility were employed in the sport project TRY Rugby-SP. We also verified how Corporate Governance influenced the major stakeholders - British Council and Premiership Rugby, and the reasons that led them to have credibility in the SESI-SP and provide a financial support for this project. The data were collected using triangulation with these tools: Observation and direct participation of one researcher and document analysis and interviews. The subjects of this study were the stakeholders that provided financial support for this project. SESI-SP management system allied with good corporate governance practices were essential to attract stakeholders`interest. In this way, we contributed to sports organizations understand and employ the best practices of corporate governance, enhancing its institutional image face its potential stakeholders and attracting increased investments for implementation of their projects
\end{abstract}

Keywords: Corporate Governance, Corporate Governance in Sport, Stakeholders. 


\section{INTRODUÇÃO}

Nos últimos anos, o esporte ganhou destaque no cenário nacional, com a vinda de megaeventos esportivos. Fator que contribuiu para que diversas organizações ampliassem o seu interesse em investimentos e desenvolvimento de projetos nesta área. Entretanto, muitas organizações esportivas ainda possuem um perfil amador e sequer possuem um modelo de gestão estruturado e organizado, nem mesmo executam as boas práticas de Governança Corporativa (GC). Não sendo capazes de demonstrarem legitimidade perante um grupo ou indivíduo, que poderia afetar ou ser afetado pelos objetivos de uma determinada organização, ou seja, seus possíveis stakeholders (Freeman, 1984), dificultando assim as suas perspectivas para captação de recursos.

A importância da GC no Esporte tem sido amplamente intensificada à medida que organizações esportivas, anteriormente detentoras de um perfil amador em sua gestão, passam a ser gerenciadas por profissionais (Ferkins, Shilbury, \& McDonald, 2005). As boas práticas de GC proporcionam o alinhamento de interesses com a finalidade de preservar e otimizar o valor de uma determinada organização, facilitando o seu acesso a recursos, contribuindo desta forma para sua longevidade (IBGC, 2009). De tal modo, ao adotarem os princípios e as boas práticas da GC, as organizações esportivas poderão reorganizar sua estrutura administrativa e financeira, atraindo assim maiores investimentos (D. S. P. Marques \& Costa, 2009).

Por meio de um estudo de caso, este relato analisa a GC de uma entidade sem fins lucrativos -

SESI-SP - e sua importância sob a ótica de seus principais stakeholders - British Council e Premiership Rugby - envolvidos na implantação e desenvolvimento do projeto esportivo TRY Rugby-SP. Tal projeto possui o objetivo de oportunizar a prática dessa modalidade aos alunos da rede escolar do SESI-SP e comunidade.
Espera-se demonstrar que as boas práticas de governança adotadas pelo SESI-SP foram essenciais para atrair o interesse de seus stakeholders $\mathrm{e}$ consequentemente os recursos necessários para desenvolvimento deste projeto. A partir dessa análise, espera-se contribuir para que outras organizações esportivas possam compreender e se utilizarem dos princípios da GC. Deste modo, as organizações esportivas poderão reconhecer e ampliar sua legitimidade diante de prováveis stakeholders, conseguindo assim maiores investimentos e subsídios.

O trabalho inicia-se apresentando o Contexto Investigado onde se caracterizam as organizações esportivas que fizeram parte deste estudo. Ainda nesse tópico apresentam-se os conceitos da GC, como ela se aplica dentro de organizações esportivas e como elas se relacionam com os seus stakeholders. Na sequência identifica-se a situação-problema e demonstra-se qual intervenção foi realizada. A partir daí, esclarecem os métodos de análise dessa intervenção, gerando os resultados deste estudo. Por último, são realizadas as conclusões e apresentadas a contribuição tecnológica social de nosso trabalho, bem como as suas limitações.

\section{CONTEXTO INVESTIGADO}

Em 09 de outubro de 2009 o Comitê Olímpico Internacional anunciou a decisão de incluir o rúgbi como modalidade nos Jogos Olímpicos do Rio 2016 (Estadão, 2009). Fato este que gerou maior visibilidade a esta modalidade esportiva com características amadoras até então e que, a partir daí, começa a obter maiores investimentos. A International Rugby Board (IRB) e o Comitê Olímpico Internacional elegem o Brasil como um dos países para desenvolvimento estratégico dessa modalidade esportiva (J. C. Marques \& Cafeo, 2014). Em 2011, o rúgbi passa a ser visto como o esporte com maior possibilidade de crescimento no país 
(DELOITTE, 2011). Neste mesmo ano, o SESI-SP foi convidado pelo British Council e pela Premiership Rugby, entidades internacionais que impulsionadas pelo cenário favorável ao crescimento do rúgbi no Brasil, procuravam uma organização esportiva, para desenvolvimento de um projeto esportivo. Scott Watson, Gerente do Projeto de Rúgbi no Brasil pela Premiership Rugby explicou: “O rúgbi fará parte do programa das Olimpíadas pela primeira vez em 2016. Portanto, este é um momento crucial para desenvolver um projeto como este" (Premiershiprugby.com, 2015). Assim, surge o projeto TRY Rugby-SP, parceria entre SESI-SP, British Council e Premiership Rugby visando proporcionar a prática desta modalidade aos alunos da rede escolar do SESI-SP e da comunidade em geral.

O trabalho é iniciado apresentando as características das organizações que serão objetos deste estudo. Demonstram-se os aspectos de sua gestão que se tornaram fundamentais para o desenvolvimento do projeto esportivo Try Rugby-SP e como os conceitos de GC foram aplicados neste processo.

Caracterização da organização: SERVIÇO SOCIAL DA INDÚSTRIA - SESI-SP

Natureza: Entidade de direito privado, nos termos da lei civil, estruturada em base federativa. Criada pelo DECRETO-LEI ${ }^{\circ}$ 9.403, de 25 de junho de 1946, com a finalidade de contribuir efetivamente com a melhoria da qualidade de vida do trabalhador da indústria, seus familiares e comunidade em geral.

Propriedade do capital: Organização nacional sem fins lucrativos, mantida por recursos provenientes de contribuições mensais recolhidas compulsoriamente das indústrias do Estado de São Paulo.

Setor de atividade: Atualmente o SESI-SP promove a educação para o desenvolvimento social e econômico do país por meio de seus serviços e produtos, buscando a transferência de tecnologias sociais que elevem a produtividade da indústria e a qualidade de vida para industriários, seus dependentes e sociedade em geral. Conforme consta em seu Relatório de Gestão Anual da Divisão de Esporte e Qualidade de Vida do SESI-SP (SESI-SP, 2014), o SESI-SP entende o Esporte como uma ferramenta para a transformação social de crianças e adolescentes, oportunizando o desenvolvimento de valores essenciais para a formação desses cidadãos, tais como: respeito, ética, cooperação, trabalho em equipe, disciplina, comprometimento, superação.

Porte e localização: No Estado de São Paulo, o SESI-SP possui uma das maiores redes de ensino particular, composta por 173 escolas, presentes em 111 municípios do Estado. Ao todo, mais de 179 mil alunos estão matriculados nas modalidades Educação Infantil, Ensino Fundamental, Ensino Médio, Educação Profissional Técnico de Nível Médio e Educação de Jovens e Adultos (SP, 2015). No Esporte, o SESI-SP atua com programas que visam a iniciação, formação, treinamento e esporte de alto rendimento, além de atividades voltadas para o lazer e a qualidade de vida. Seguem alguns resultados desses serviços (SESI-SP, 2014):

- Esporte Escolar - aulas de esporte para os alunos de sua rede escolar -16.822 alunos do $6^{\circ}$ ao $9^{\circ}$ ano.

- Programa SESI-SP Atleta do Futuro atividades socio- esportivas para crianças e adolescentes - 107.867 alunos, 27 modalidades esportivas e 283 municípios atendidos.

- Treinamento Esportivo - 2.147 alunos em 16 modalidades

- Esporte de Rendimento - 700 atletas em 19 modalidades

- Jogos do SESI - competição esportiva para os trabalhadores das Indústrias - 77.481 atletas participantes em 70 municípios, competindo em 77 modalidades durante o ano de 2014.

Estrutura organizacional da empresa $e$ eventual organização para projetos: O Esporte consiste 
em uma área de atuação da Divisão de Qualidade de Vida, composta por uma Sede e Unidades Operacionais. Em sua Sede, ocorre a formatação, planejamento e controle dos projetos que serão desenvolvidos e aplicados nas Unidades Operacionais. No estado de São Paulo, o SESI-SP conta com 54 Centros de Atividades (Unidades Operacionais), os quais são geridos administrativamente por um Diretor e um Gerente Administrativo; e tecnicamente pelos responsáveis de cada área, neste caso do Esporte, por um Coordenador e um Orientador.

Compreendendo melhor a estrutura do SESI-SP, procuramos entender a estrutura dos seus stakeholders, British Council e Premiership Rugby e suas principais características.

Caracterização da organização: BRITISH COUNCIL

Natureza: O British Council é um órgão público executivo, não departamental, sendo, portanto, independente operacionalmente do Governo do Reino Unido e não exercendo funções em nome da Corte Britânica. Foi fundado em 1934.

Propriedade do capital: Organização estrangeira, sem fins lucrativos, a qual possui grande parte de sua receita oriunda dos cursos e projetos que desenvolve. Recebe também subsídios do governo do Reino Unido.

Setor de atividade: Possui como principal objetivo o fortalecimento dos laços entre o Reino Unido e demais países por meio da construção de relacionamentos mutuamente benéficos nas áreas de educação, artes, esportes e língua inglesa.

Porte e localização: O British Council trabalha para construir uma relação de confiança e cooperação entre o Reino Unido e demais países. No mundo, estão presentes em mais de cem países, sendo doze no Continente Americano. No Brasil, instalou-se em 1945 e atualmente possui três escritórios: Recife, Rio de Janeiro e São Paulo.
Estrutura organizacional da empresa e eventual organização para projetos:

Possui uma Diretoria Executiva responsável pela estratégia global, direção e gestão da organização. O Conselho é considerado como um guardião da organização, sendo em última instância responsável por ela. No tocante ao Esporte, o British Council entende que trata-se de uma ferramenta de inclusão e desenvolvimento sociais. Seus programas utilizam o esporte como inspiração para engajar, construir habilidades, desenvolver a autoconfiança e oferecer novas oportunidades de aprendizado, especialmente para os jovens. No Brasil, desenvolve 03 grandes projetos: Premier Skills - parceria internacional com a Premier League, que utiliza o futebol como uma ferramenta para criar um futuro melhor para jovens em 25 países; Programa Liderança Juvenil através do Esporte, com o objetivo de capacitar jovens com diversas técnicas para que eles desenvolvam suas habilidades de liderança através do esporte, da cultura e das artes; Projeto TRY Rugby-SP, utilizado como referência para a análise deste estudo, cujo objetivo é utilizar o rúgbi como uma ferramenta para engajar crianças e jovens, promovendo saúde, educação e resultados sociais, bem como visa aumentar o número de praticantes dessa modalidade (Britishcouncil.org.br, 2015).

\section{Caracterização da organização: PREMIERSHIP RUGBY}

Natureza: Entidade Privada, fundada em 1987 para gerenciar a principal competição de rúgbi no Reino Unido.

\section{Propriedade do capital: Organização} estrangeira, a qual possui grande parte de sua receita oriunda dos patrocinadores da Liga.

Setor de atividade: gerencia as competições de rúgbi na Inglaterra, promovendo e estimulando o desenvolvimento desta modalidade naquele país. 
Porte e localização: A Premiership Rugby é considerada uma das maiores ligas esportivas dessa modalidade no mundo. Sua principal competição, a Aviva, reúne as 12 (doze) melhores equipes profissionais de rúgbi.

\section{Estrutura organizacional da empresa e} eventual organização para projetos: Em sua estrutura corporativa, possuem uma Diretoria de Comunidade e Responsabilidade Social Corporativa. Cabe a esta Diretoria executar projetos sociais voltados para a disseminação dos valores fundamentais do rúgbi, proporcionando a inclusão social e a formação cidadã de crianças e adolescentes por meio desta modalidade esportiva. Entre esses projetos destacam-se: Programa HITZ, utiliza o rúgbi com o objetivo de ampliar a resiliência e a autoconfiança de jovens menos favorecidos socialmente; Aviva Trackling Numbers, programa temático que integra sessões de rúgbi com aulas interativas de Matemática; Something to Chew On, projeto que integra o rúgbi com hábitos de saúde e bem estar, ensinando crianças a adquirirem uma alimentação saudável. Além desses projetos, a Premiership exige que cada um dos 12 (doze) clubes que participam da Aviva - competição principal do rúgbi - possuam suas respectivas diretorias para realização de ações e projetos sociais voltados a comunidade (Premiershiprugby.com, 2015).

Analisando as características dessas organizações, identificou-se que todas possuem um histórico extenso de ações voltadas ao esporte, com características profissionais que as diferem de outras entidades amadoras. Desta forma, segundo Ferkins, Shilbury, \& McDonald, (2005) organizações como estas reconhecem, de forma mais significativa, a importância da governança corporativa.

$\mathrm{O}$ relacionamento entre os gestores e seus stakeholders depende da natureza, qualidade e características de sua interação (Donaldson \& Preston, 1995). Diante desse contexto e por possuírem estrutura de gestão profissional, princípios e valores semelhantes na condução dos seus serviços, as três organizações se uniram para desenvolvimento do projeto TRY RugbySP. Tal projeto visa a implantação de atividades de rúgbi aos alunos da rede escolar do SESI-SP e da comunidade, além da transferência do conhecimento de técnicos ingleses da Premiership Rugby para os professores do SESI-SP.

O SESI-SP possui como objetivo principal oportunizar novas experiências motoras, conceituais e culturais aos seus alunos, além de estimular a prática esportiva e adoção de um estilo de vida saudável. Paulo Skaf, Presidente do SESI-SP destaca o esporte como uma ferramenta para a educação:

Queremos oferecer novas oportunidades de práticas esportivas aos nossos jovens, pois acreditamos no esporte como ferramenta para a educação. Por meio da democratização do acesso à prática esportiva, temos a oportunidade de revelar novos talentos, contribuir com o fortalecimento do esporte nacional e a melhoria da qualidade de vida das pessoas (Skaf, 2012).

O rúgbi é um esporte com valores que desenvolvem os jogadores dentro de um contexto social e moral. Os valores fundamentais do jogo são: integridade, paixão, solidariedade, disciplina e respeito (Rugbyready.worldrugby.org, 2015). Esse foi um dos motivos do SESI-SP para a escolha dessa modalidade, conforme identifica o Especialista em Qualidade de Vida do SESI-SP, Felipe de Pilla Varotti, responsável técnico pelo projeto:

Desde o início, percebemos o diferencial do projeto e dessa modalidade, por meio do interesse demonstrado por todos os envolvidos e, principalmente, pelos valores positivos ensinados e repassados aos nossos alunos. O rugby é uma modalidade totalmente inclusiva, na qual todos os alunos têm participação efetiva, independentemente de suas condições técnicas ou físicas. Além disso, conceitos como trabalho em equipe, respeito, liderança, disciplina e espírito 
esportivo são diariamente trabalhados nas aulas (SESI, 2015, p.9).

Em seu escopo básico o projeto prevê a permanência de um técnico inglês durante um período de 10 meses em uma unidade do SESI, onde o mesmo executará atividades permanentes - aulas; atividades eventuais - clínicas, oficinas, festivais esportivos; e transferência de conhecimento - capacitação aos professores do SESI-SP. Implantado em 2012 em 12 unidades do SESI-SP, o projeto contemplou naquele ano o atendimento a 9.349 alunos. Atualmente o projeto é desenvolvido em 24 unidades do SESI-SP, tendo atendido mais de 14 mil alunos desde sua implantação (SESI, 2014).

Esta parceria prevê uma gestão integrada do projeto por meio de um Convênio de Cooperação Técnica, em que cada uma das partes interessadas possui uma responsabilidade definida em contrato, seja administrativa, financeira ou técnica, garantindo assim melhor relacionamento entre o SESI-SP e seus stakeholders. Essa relação entre as organizações esportivas e seus stakeholders foi classificada por Byers, Slack \& Parent (2012) como de suma importância para a gestão dessas organizações.

Por meio deste relato técnico descreve-se a experiência vivenciada pelo SESI-SP, refletindo o pensamento dos autores e sendo escrito com base no rigor científico e metodológico (Biancolino, Kniess, Maccari, \& Jr., 2012). O estudo é realizado para responder à seguinte questão: qual o papel da prática da GC dentro de uma organização esportiva e como ela influencia os stakeholders durante o desenvolvimento de um projeto esportivo?

Para isso espera-se verificar se existe GC na organização estudada - SESI-SP - e como esta entidade se utilizou dos princípios da Governança para o desenvolvimento do projeto Try Rugby-SP. Nesta análise é considerada a ótica de seus stakeholders, British Council e Premiership Rugby, ou seja, entidades que participam diretamente deste projeto, interessados em sua evolução ou afetados pelos seus resultados (Orth \& Prikladnicki, 2009).

\section{REVISÃO DE LITERATURA}

Serão apresentados os principais conceitos norteadores deste estudo. Primeiro, conceitua-se a GC, suas características no cenário brasileiro e como esta se aplica dentro do Esporte. Assim é possível avaliar se o SESI-SP desenvolve as boas práticas da GC em sua gestão. Por fim, compreende-se o conceito de stakeholders, fundamental para a análise e compreensão desta pesquisa - neste caso British Council e Premiership Rugby - e decifra-se sua relação com a GC existente no SESI-SP e as implicações para o desenvolvimento deste projeto.

Governar é dirigir uma organização e tomar decisões que são consequentes, estratégicas e impactantes, geralmente em nome de terceiros (Shilbury, Ferkins, \& Smythe, 2013). Os indivíduos que têm capacidade para gerir negócios não são, necessariamente, aqueles que possuem os recursos para implementá-los (Souza, Murcia, \& Marcon, 2011). Desta forma, destaca-se uma série de mecanismos ou sistemas que governam o poder decisório dentro de uma organização, conjunto este denominado Governança Corporativa (D. S. P. Marques \& Costa, 2009).

A GC pode ser definida por um processo de controle, delegação e poder, no qual um indivíduo ou grupo dirige uma organização, definindo suas características e seu futuro, bem como selecionando, incentivando e supervisionando outros indivíduos para agirem dentro desta organização de acordo com os seus interesses (M. A. de S. Ribeiro, 2012). Neste processo, envolvem-se os relacionamentos entre proprietários, Conselho de Administração, Diretoria e Órgãos de Controle (IBGC, 2009). Trata-se de um conjunto de regras visando minimizar os problemas, equilibrando a 
competitividade e produtividade da empresa com uma gestão responsável e transparente (Marques, 2007).

Os conceitos acima expostos foram fundamentais ao SESI-SP no início desta parceria. Era necessário estabelecer regras e procedimentos, devido ao envolvimento de 12 (doze) diferentes unidades operacionais, com seus respectivos gestores e profissionais envolvidos, além dos 12 treinadores ingleses da Premiership Rugby.

A GC tem sido fruto de amplas discussões que identificam a necessidade de se pensar como melhor governar, organizar e possibilitar maior transparência no processo decisório de empresas (H. C. M. Ribeiro, 2014). Desta forma, garante melhor performance, melhor monitoramento e proteção de seus investidores (M. Marques, 2007). Nos últimos anos, a governança corporativa tem se fortalecido por meio da definição de códigos e cartilhas, bem como em função da adoção de seus princípios por parte das instituições (Duarte, Cardozo, \& Vicente, 2012).

No caso do Brasil, bem como dos demais países emergentes, a possibilidade de captação de recursos estrangeiros faz com que ocorra a adaptação e adoção de boas práticas de governança por parte das empresas (Duarte et al., 2012). Essa foi uma das necessidades percebidas pelos parceiros para o desenvolvimento deste projeto. Todas as entidades envolvidas aportaram recursos financeiros para o desenvolvimento deste projeto, e, uma vez que os custos do projeto eram divididos entre elas, verificou-se a necessidade de implantação das boas práticas e dos princípios da GC para a sua condução.

Segundo o Instituto Brasileiro de Governança Corporativa (IBGC, 2009), a GC está pautada por meio dos seguintes princípios:

- Transparência - Oferecer para todas as partes interessadas as informações de seu interesse, não se preocupando apenas em informar aquelas impostas por leis e regulamentos. Quanto maior a transparência, maior será a confiança, seja do ambiente interno ou externo.

- Equidade - Caracteriza-se pelo tratamento justo de todos os sócios e demais partes interessadas (stakeholders), evitando atitudes ou decisões discriminatórias.

- Prestação de Contas (accountability) - Cabe aos agentes da governança prestarem contas de toda a sua atuação, se responsabilizando pelos seus atos, decisões e/ou omissões.

- Responsabilidade Corporativa - Os agentes de governança devem buscar a sustentabilidade das organizações, visando à sua longevidade, adotando medidas que levem em consideração fatores de ordem social e ambiental.

Baseado nesses princípios, as entidades parceiras do projeto TRY Rugby-SP criaram um modelo de relatório para prestação de contas, mantendo a transparência entre as mesmas. Reuniões periódicas eram realizadas para avaliação e alinhamento estratégico das ações e dos objetivos, uma vez que algumas alterações se fizeram necessárias após o início do projeto. Era necessário compreender não apenas a maneira como essas organizações eram dirigidas, mas também a forma de melhorar os métodos de interação e eficiência de todas as redes de governança (Groeneveld, 2009).

Em organizações esportivas, o controle de suas atividades não é exercido por pessoas que se beneficiem diretamente de seus recursos. Assim, a GC torna-se essencial para que essas entidades sejam administradas de maneira eficaz, sobrevivendo às circunstâncias econômicas que cercam o cenário esportivo (Hamil, Morrow, Idle, Rossi, \& Faccendini, 2010). Ainda segundo os autores, a GC possibilita o engajamento dos stakeholders dessas entidades, definindo suas responsabilidades para que por meio deles, os recursos sejam garantidos para a continuidade de suas atividades. Desta forma, um bom sistema de governança deve levar 
em consideração os interesses de todos os envolvidos, favorecendo assim a transparência dentro dessa organização.

Freeman (1984) classificou a Teoria dos Stakeholders, identificando que tratava-se de um grupo ou indivíduo que poderia afetar ou ser afetado pelos objetivos de uma determinada organização. Sotiriadou (2009) identifica que os stakeholders aderem a relações interorganizacionais com outros interessados para garantir recursos. $\mathrm{O}$ autor afirma que a Teoria dos Stakeholders é um método adequado para construção dessas relações e que dessa forma, os stakeholders estabelecem um elo para a realização de seus objetivos. Assim se fez o relacionamento entre SESI-SP, British Council e Premiership Rugby.

A Teoria dos Stakeholders pode ser compreendida como uma teoria de gestão organizacional e ética que aborda de uma forma explícita a moral e os valores como características centrais da gestão das organizações (Phillips, Freeman, \& Wicks, 2003). Os autores ainda afirmam que todas as teorias de gestão estratégica possuem algum conteúdo moral, embora seja muitas vezes implícito.

Mainardes, Alves, Raposo, \& Domingues (2010) conceituam gestão de stakeholders como sendo necessária para que as organizações reconheçam, analisem e examinem as características dos indivíduos e grupos que influenciam ou são influenciadas por elas. Os autores sugerem que a classificação é realizada em três diferentes níveis: 1- identificação dos stakeholders; 2- desenvolvimento de processos que reconheçam suas necessidades e interesses; 3- construção de relacionamentos com os stakeholders. Esses níveis foram percebidos no projeto. A identificação dos stakeholders ocorreu no início, quando o SESI-SP identificou o potencial, tanto do British Council, pela sua tradição e responsabilidade corporativa, quanto da Premiership Rugby, pela sua vasta e reconhecida expertise na modalidade. Na sequência, traçaram em conjunto o planejamento do projeto, levando em consideração a necessidade e interesse de todos. Por fim, estabeleceram a parceria e consequentemente, um relacionamento entre as entidades.

Mitchell, Agle, \& Wood (1997) investigaram as percepções dos gestores sobre as características dos stakeholders, bem como sua saliênca no que se referia aos seguintes aspectos:

- Poder - do stakeholder, para influenciar a empresa;

- Legitimidade - no relacionamento do stakeholder com a empresa, considerando se as ações dessa organização são convenientes, adequadas ou apropriadas com sua forma de pensar e suas crenças;

- Urgência - de acordo com a reivindicação do stakeholder e a atenção imediata que o mesmo demanda para a empresa.

Finalmente, Mitchell et al. (1997) definem a Saliência como o grau em que os gestores priorizam os pedidos dos seus stakeholders, resultado da combinação dos atributos anteriores. Para Bourne \& Walker (2006), este ponto de vista identifica a necessidade de ampliar a negociação entre essas partes, ajustando as variáveis intermediárias, tais como confiança e comprometimento, para que dessa forma atinjam os resultados positivos.

No tocante à execução de projetos, os stakeholders exercem influência significativa e que deve ser altamente considerada pelos gestores. Segundo Orth \& Prikladnicki (2009), os stakeholders são pessoas ou entidades que participam diretamente ou indiretamente de um projeto, interessados em sua evolução, ou ainda, quando são afetados pelos seus resultados. Olander (2007) identifica que uma importante consideração para a equipe de gestão de projetos é identificar e analisar os stakeholders que possuem uma influência além das decisões do projeto. Com isso, beneficia-se o processo que maximiza as contribuições dos stakeholders, 
diminuindo qualquer possibilidade de impacto negativo (Bourne \& Walker, 2006).

Desta forma, baseado nos conceitos e trabalhos apresentados anteriormente, este estudo procura avaliar se o SESI-SP utilizou os princípios de GC para desenvolvimento do projeto TRY Rugby-SP e se os mesmos podem ser identificados pelos seus principais stakeholders - British Council e Premiership Rugby.

\section{DIAGNÓSTICO DA SITUAÇÃO PROBLEMA}

O TRY Rugby-SP foi o primeiro projeto desenvolvido pela Divisão de Qualidade de Vida do SESI-SP com uma parceria com entidades internacionais e de grande expressão e representatividade em suas respectivas áreas de atuação. A sua aprovação passou pela avaliação do Conselho Administrativo do SESI-SP. A entidade destinou uma gama de recursos para sua execução.

O projeto previa o relacionamento constante com demais stakeholders, sejam as demais entidades parceiras, sejam as próprias unidades operacionais do SESI-SP e todas as pessoas que estariam envolvidas neste processo: treinadores ingleses da Premiership Rugby - os quais encontrariam um país com cultura e idioma diferentes; professores do SESI-SP - que não tiveram acesso à modalidade na sua formação acadêmica; gestores das unidades - que precisariam compreender todas as etapas e procedimentos necessários para o desenvolvimento do projeto; e por fim, os próprios alunos, que desconheciam o rúgbi e precisariam ser conscientizados e motivados a praticalo.

No cenário esportivo nacional, representou uma ação inédita para o desenvolvimento desta modalidade esportiva, uma vez que oportunizaria o acesso à prática para aproximadamente 10 (dez) mil alunos em seu primeiro ano de implementação, informação esta ratificada pelo Presidente da Confederação Brasileira de Rugby, Sami Arap Sobrinho:

$\mathrm{O}$ recém-lançado projeto "Try-Rugby SP" é de suma importância para o desenvolvimento do rúgbi no Brasil. Imagine o que significa alcançar dez mil jovens de oito a 17 anos no Estado de São Paulo, em parceria com o SESI-SP (respaldado pela FIESP), contando com a reputação do British Council e da Aviva Premiership. Estou certo de que o projeto terá êxito e será replicado em outras unidades do país (Arap, 2012).

Considerando esse contexto e a relevância do projeto, nos primeiros meses de realização, houve uma constante preocupação da equipe gestora de todas as entidades em realizar avaliações e reuniões constantes, para detecção de possíveis situações que pudessem comprometer o projeto. Assim, identificou-se a necessidade de adoção dos princípios e práticas da boa governança, estabelecendo procedimentos e ações visando transparência, prestação de contas, equidade, ética e reponsabilidade social entre as entidades. Segundo (Marques \& Costa, 2009), a adoção da GC ajuda os clubes e entidades esportivas a reconstruírem sua estrutura administrativa e financeira, seja pela organização de sua estrutura interna, seja pela atração de investimentos motivada por essa mudança.

Um plano de ação foi elaborado, no qual se estabeleceram os documentos de controle necessários e o fluxo de comunicação que seriam utilizados:

- Relatório Estatístico de Produção - todas as entidades adotaram um mesmo modelo para controle mensal dos resultados;

- Relatório de Avaliação Qualitativa do Projeto tanto os técnicos ingleses quanto os profissionais do SESI-SP relatavam mensalmente as situações vivenciadas para o desenvolvimento das atividades;

- Acompanhamento Trimestral de Despesas todas as entidades envolvidas apresentavam as despesas realizadas e o investimento total no projeto; 
- Calendário de reuniões de gestão - bimestrais ou trimestrais, conforme necessidade, envolvendo a equipe gestora das entidades, para definição e planejamento conjunto de todas as ações envolvendo o projeto;

- Calendário de visitas Técnicas - realizadas pela equipe de gestão das entidades nas unidades operacionais que foram sedes do projeto, levantando informações e verificando o desenvolvimento das atividades;

- Calendário de Ações Técnicas compartilhamento de todas as informações sobre o projeto, envolvendo eventos, reuniões técnicas e capacitações com professores.

- Relatório Mensal do projeto - com todas as informações, quantitativas, qualitativas e dos recursos utilizados, para compartilhamento com a alta direção das entidades.

- Fluxo de Comunicação - estabelecendo os processos e quem seriam os responsáveis por cada um deles. Desta forma, as ações técnicas seriam discutidas entre SESI-SP e Premiership Rugby, já as questões administrativas seriam discutidas em conjunto entre as três Entidades.

Uma vez identificada a situação problema e quais foram as medidas adotadas pelo SESI-SP, procuramos então avaliar se as mesmas estão relacionadas com os princípios da Governança Corporativa e se essas produziram resultados significativos após sua implementação. Para isto, utilizamos a pesquisa qualitativa, que fornece uma visão profunda de um fenômeno complexo (Fawcett et al., 2014), sendo portanto exploratória e conveniente uma vez que os pesquisadores não conhecem as variáveis importantes a serem analisadas (Creswell, 2010). Assim, exploramos todos os conceitos que foram utilizados para realizar a intervenção e compreender todo o contexto envolvido no projeto TRY Rugby-SP.

\section{METODOLOGIA}

Por meio de um estudo de caso, o qual segundo Mariotto, Zanni, \& Moraes (2014) é um instrumento importante da investigação no campo da gestão, utilizado como um exemplo a ser seguido ou de como algo pode acontecer, este trabalho coletou os dados utilizando as seguintes ferramentas:

- Observação e participação direta de um dos pesquisadores: desde o início do projeto Try Rugby-SP, um dos pesquisadores atua com sua gestão, sendo responsável pelo acompanhamento técnico das ações que são desenvolvidas. Essa situação provocou maior facilidade na obtenção das informações necessárias para este estudo bem como oportunizou o acompanhamento de todo o processo, desde a implantação até a execução da intervenção e análise dos resultados.

- Análise de Documentos - foram utilizadas as informações constantes nos sites das Entidades, para verificar se as mesmas apresentam características de GC. Também foram analisados os relatórios gerenciais do SESI-SP e do Projeto para verificar se as intervenções e conceitos utilizados impactaram no resultado quantitativo e qualitativo.

- Entrevistas - foram realizadas entrevistas semiestruturadas com os principais gestores de cada uma das entidades parceiras, capazes de influenciar ou serem influenciados pelos demais stakeholders envolvidos na gestão do projeto. Pelo SESI-SP, participou o Sr. Eduardo Augusto Carreiro, Gerente Executivo de Esporte e Vida Saudável. Pelo British Council, participou a Sra. Amanda Lima, Gerente de Esportes no Brasil. Pela Premiership Rugby, participou o Sr. Wayne Morris, Diretor de Comunidade e Responsabilidade Social Corporativa. As questões basearam-se nos conceitos principais deste estudo: governança corporativa e stakeholders. 
Utilizou-se a triangulação, fonte de informação difundida no âmbito acadêmico, que utiliza as entrevistas, os documentos e a observação para aumentar a validade e confiabilidade de uma pesquisa, diminuindo assim suas inconsistências (Paiva Júnior, Leão, \& Mello, 2011).

Os sujeitos deste estudo foram os stakeholders principais envolvidos, somente aqueles que aportaram recursos financeiros para a execução do projeto, portanto SESI-SP, British Council e Premiership Rugby. Nesta análise não foram considerados os demais stakeholders, tais como gestores das unidades, treinadores da Premiership Rugby, professores e alunos do SESI-SP.

\section{ANÁLISE E DISCUSSÃO DOS RESULTADOS}

Para análise dos dados utilizou-se o modelo de Análise de Conteúdo, adaptado de (H. C. M. Ribeiro, 2014), categorizando a interpretação dos dados extraídos das entrevistas, análise documental e da observação direta. Para isso, as informações foram descritas conforme segue:
a) Entendimento do SESI-SP sobre a GC
b)Aplicação dos princípios da GC no SESI-SP
c) Relacionamento do SESI-SP com seus stakeholders
d)Aplicação dos princípios da GC no projeto TRY Rugby-SP
e) Influência da GC para os stakeholders do SESI-SP

\section{Descrição dos resultados obtidos}

a) Entendimento do SESI-SP sobre GC

$\mathrm{O}$ dirigente do SESI-SP entende que "é um conjunto de ações que visam garantir uma boa gestão, mais focada em resultados, no desenvolvimento de pessoas, mais focada na responsabilidade social empresarial e no processo decisório".

Essas informações vão ao encontro do conceito que relaciona uma boa governança com a percepção de bons resultados (M. A. de S. Ribeiro, 2012). É um conjunto de regras, princípios e práticas, que norteiam o processo decisório (Weitzner \& Peridis, 2011).

b) Aplicação dos princípios da GC no SESI-SP

Identificou-se que a entidade se preocupa com a Transparência, mantendo em seu site, informações referentes ao seu planejamento estratégico e suas diretrizes orçamentárias. Neste mesmo site, também é possível identificar a Prestação de Contas, por meio do relatório gerencial e das informações sobre as despesas com recursos humanos (http://www.sesisp.org.br, recuperado em 15, julho, 2015). O SESI-SP possui diversos projetos de Responsabilidade Social Corporativa, realizando ações para os seus próprios colaboradores, bem como atendimento às Indústrias com programas de educação para a sustentabilidade e desenvolvimento social (http://www.sesisp.org.br/responsabilidade-social/, recuperado em 15, julho, 2015). Em relação à Ética, seu dirigente descreveu que "o SESI-SP possui o seu código de Éticas interno, desenvolvido em conjunto com os seus colaboradores. Da mesma forma, valorizamos esse princípio nas ações que desenvolvemos para as Indústrias”. Em seu ambiente interno, observa-se uma frequente preocupação com o desenvolvimento e melhoria dos seus processos de gestão.

A prática da GC poderá ocorrer em diversas áreas, inclusive no Esporte (Ferkins \& Shilbury, 2012). Está relacionada ao aperfeiçoamento da gestão e controle das entidades esportivas (Hamil et al., 2010).

c) Relacionamento do SESI-SP com seus stakeholders

Neste caso, analisou-se o relacionamento do SESI-SP especificamente com os stakeholders do projeto. Por meio da observação direta de um dos pesquisadores entendeu-se que o relacionamento existe de uma forma permanente, onde as entidades 
conseguem se respeitar. Buscam compreender a realidade de cada um dos seus stakeholders e compartilhar as informações, sempre construindo e planejando as ações em conjunto com os mesmos.

Esse ponto de vista também pôde ser observado nas respostas dos entrevistados. O gestor da Premiership sinaliza que "as três organizações agregam muito valor para o desenvolvimento do projeto $\mathrm{e}$ se complementam". Para a gestora do British Council, "as organizações se respeitam e respeitam também todos os seus trâmites e processos internos”. Já o gestor do SESISP aponta que: "esse relacionamento é muito importante e sempre tem que existir. Quando você consegue trabalhar junto, você engrandece o processo. Temos que aprender com os parceiros, nos unirmos para conseguir mais e melhor, para conseguir trocar as boas práticas". Segundo Leal \& Saito (2003) é fundamental que os gestores possam agir no melhor interesse dos stakeholders envolvidos na organização.

d) Aplicação dos princípios da GC no projeto TRY Rugby-SP

Quanto aos princípios da GC no desenvolvimento do projeto, parece haver um consenso em relação à sua aplicação. Em todas as entrevistas os gestores apontam que o projeto é gerenciado de forma tríplice, havendo principalmente transparência, ética e prestação de contas entre as entidades.

Analisando os documentos gerenciais, identificam-se os princípios da GC nos quais esses documentos foram criados:

- Relatório Estatístico de Produção e o Relatório de Avaliação Qualitativa do projeto - reforça a Transparência, Ética e Equidade no repasse das informações sobre o projeto, uma vez que todas as entidades adotaram um mesmo modelo para controle e avaliação dos resultados;

- Acompanhamento Trimestral de Despesas reforça a Transparência e a Prestação de Contas, uma vez que todas as entidades envolvidas apresentam as despesas realizadas e o investimento total no projeto. Conforme cita o gerente do SESI-SP "existe uma relação de prestação de contas de um para o outro, mostramos as planilhas abertas, para sabermos o grau de responsabilidade destinado ao projeto";

- Calendário de reuniões de gestão e Fluxo de Comunicação - reforça a Equidade e a Transparência entre as entidades, demonstrando a importância da participação de todos para o desenvolvimento do projeto;

Os dirigentes de uma organização devem garantir um relacionamento transparente e de longo prazo com seus stakeholders, definindo a estratégia de comunicação com esse público (IBGC, 2009).

\section{e) Influência da GC para os stakeholders}

do SESI-SP

Para a gestora do BC, a GC demonstrada pelo SESI-SP exerce um papel fundamental pois, por meio dela, "conseguimos conversar e desenvolver projetos, principalmente sociais, que alcançam interesses mútuos em participação em massa, divulgação do esporte e seus beneficios, engajamento social e implantação de diversos conhecimentos". O gestor da Premiership reforça que por meio desta GC e da estrutura apresentada desenvolveram o "primeiro programa internacional em grande escala da Premiership".

Para o gestor do SESI-SP:

“a transparência e prestação de contas geram uma confiança muito grande no parceiro, pois sabem que faremos bom uso dos recursos que são investidos. Os princípios da prática de governança acabam influenciando, tanto da parte deles, que nos ensinaram muito, tanto da nossa parte que também ensinamos. Isso gera credibilidade para a parceria”.

Caberá ao gestor de uma organização esportiva identificar o grau de confiança que sua organização 
transmite aos seus stakeholders (Miragaia, Ferreira, \& Carreira, 2014) e se os mesmos sofrem influência da governança corporativa, por meio de seus princípios $(\mathrm{H}$. C. M. Ribeiro, 2014).

\section{CONCLUSÕES}

Demonstrou-se por meio deste estudo como os stakeholders identificam a capacidade de governança corporativa de uma determinada organização e, a partir daí, investem seus recursos para desenvolvimento de projetos. Ou seja, a GC torna-se fundamental para o sucesso das organizações esportivas (H. C. M. Ribeiro, 2014) à medida em que possibilita o engajamento dos stakeholders dessas entidades, definindo suas responsabilidades, para que por meio deles, os recursos sejam garantidos para continuidade de suas atividades (Hamil et al., 2010).

Desta forma, adotar as boas práticas de governança torna-se um fator primordial para que organizações esportivas consigam valorizar sua imagem institucional perante os seus possíveis stakeholders, atraindo maiores investimentos e credibilidade para a execução de seus projetos esportivos.

Um bom sistema de GC é aquele onde os gestores levam em consideração os interesses de diferentes grupos de stakeholders (Senaux, 2008). Este sistema é impactado profundamente pela forma como essas organizações esportivas são geridas (Ferkins \& Shilbury, 2015). Neste estudo, o sistema de gestão e as características do SESI-SP foram fundamentais para atrair o interesse de stakeholders para o desenvolvimento do projeto TRY Rugby-SP.

Como limitações deste estudo aponta-se o fato do mesmo ter como sujeitos apenas os stakeholders que aportaram recursos financeiros no projeto, o que daria uma oportunidade futura de identificar a influência da governança nos demais stakeholders, tais como alunos, coordenadores e professores das unidades onde o mesmo é realizado, entre outros. O estudo foi baseado em um estudo de caso, o que deverá gerar uma cautela na replicação das ferramentas aqui apresentadas por parte de outras entidades esportivas. Estas deverão cuidar para respeitar as suas características próprias e do ambiente em que estão inseridas.

\section{REFERÊNCIAS}

Arap, S. (2012). Presidente da CBRu fala sobre os próximos planos do Brasil no rúgbi. http://maquinadoesporte.uol.com.br/artigo/entrevistasami-arap-sobrinho_308.html.

Biancolino, C. A., Kniess, C. T., Maccari, E. A., \& Jr., R. R. (2012). Protocolo Para Elaboração De Relatos De Produção Técnica. Revista de Gestão E Projetos, 3(2), 294-307. http://doi.org/10.5585/gep.v3i2.121

Bourne, L., \& Walker, D. H. T. (2006). Using a Visualising Tool to Study Stakeholder Influence - two Australian exmples. The Project Management Journal, 37(1), 5-21. Retrieved from www.mosaicprojects.com.au

Britishcouncil.org.br,. (2015). British Council| Brasil. Retrieved 13 June 2015, from http://www.britishcouncil.org.br

Byers, T., Slack, T., \& Parent, M. (2012). Key Concepts in Sport Management. Sage.

Creswell, J. W. (2010). Projeto de pesquisa Métodos Qualitativo, Quantitativo e Misto. (D. da Silva, Ed.) (3rd ed.). Porto Alegre: Artmed.

Deloitte,. (2011). Muito Além do Futebol Estudo sobre esportes no Brasil. 
A Prática da Governança Corporativa e sua Influência Para os Stakeholders Envolvidos no Desenvolvimento de um Projeto Esportivo do Sesi-SP

Donaldson, T., \& Preston, L. E. (1995). The Stakeholder Theory of the Corporation: Concepts,

Evidence and Implications. Academy of Management, 20(1), 65-91.

Duarte, E., Cardozo, M. A., \& Vicente, E. F. R. (2012). Governança : Uma Investigação da Produção Científica Brasileira no Período de 2000 a 2009.

Contabilidade, Gestão E Governça, 15(1), 115-127.

Estadão,. (2009). COI inclui golfe e rugby entre esportes para jogos do Rio. Retrieved from http://www.estadao.com.br/noticias/geral,coi-incluigolfe-e-rugby-entre-esportes-para-jogos-do-rio, 448447

Fawcett, S. E., Waller, M. a., Miller, J. W., Schwieterman, M. a., Hazen, B. T., \& Overstreet, R. E. (2014). A trail guide to publishing success: Tips on writing influential conceptual, qualitative, and survey research. Journal of Business Logistics, 35(1), 1-16. http://doi.org/10.1111/jbl.12039

Ferkins, L., \& Shilbury, D. (2012). Good Boards Are Strategic: What Does That Mean for Sport Governance? Journal of Sport Management, 26(1), $67-80$.

Ferkins, L., \& Shilbury, D. (2015). The Stakeholder Dilemma in Sport Governance : Toward the Notion of “ Stakeowner ." Journal of Sport Management, 29, 93-108.

Ferkins, L., Shilbury, D., \& McDonald, G. (2005). The Role of the Board in Building Strategic Capability: Towards an Integrated Model of Sport Governance Research. Sport Management Review, 8(3), 195-225. http://doi.org/10.1016/S14413523(05)70039-5
Freeman, R. E. (1984). Strategic Management: A Stakeholder Approach. Boston: Pitman Publishing Inc.

Groeneveld, M. (2009). European Sport Governance, Citizens, And The State. Public Management Review, 11(4), 421-440. http://doi.org/10.1080/14719030902989516

Hamil, S., Morrow, S., Idle, C., Rossi, G., \& Faccendini, S. (2010). The governance and regulation of Italian football. Soccer \& Society, 11(4), 373-413. http://doi.org/10.1080/14660971003780297

Instituto Brasileiro de Governança Corporativa. (2009). Código das Melhores Práticas de Governança Corporativa (4th ed.). São Paulo: IBGC.

Leal, R. P. C., \& Saito, R. (2003). Finanças Corporativas no Brasil. RAE Eletrônica, 2(2), 1-15. http://doi.org/10.1590/S1676-56482003000200005

Mainardes, E. W., Alves, H., Raposo, M., \& Domingues, M. J. (2010). Categorização por Importência dos Stakeholders das Universidades. Revista Ibero-Americana de Estratégia - RIAE, 9(2176-0756), 4-43.

Mariotto, F. L., Zanni, P. P., \& Moraes, G. H. S. M. De. (2014). What Is the Use of a Single-Case Study in Management Research ? Rae, 54(4), 358-369. http://doi.org/10.1590/S0034-759020140402

Marques, D. S. P., \& Costa, A. L. (2009).

Governança em clubes de futebol: um estudo comparativo de três agremiações no estado de São Paulo. Revista de Administração, 44(2), 118-130. Retrieved from http://www.spell.org.br/documentos/ver/6829/governan 
A Prática da Governança Corporativa e sua Influência Para os Stakeholders Envolvidos no Desenvolvimento de um Projeto Esportivo do Sesi-SP

ca-em-clubes-de-futebol--um-estudo-comparativo-detres-agremiacoes-no-estado-de-sao-paulo

Marques, J. C., \& Cafeo, M. R. G. (2014). Mulheres Fazem Isso? - Análise das Estratégias de Gestão do Rúgbi Feminino no Brasil. Podium Sport, Leisure and Tourism Review, 03(02), 26-40. http://doi.org/10.5585/podium.v3i2.91

Marques, M. (2007). Aplicação dos Princípios da Governança Corporativa ao Sector Público. Revista de Administração Contemporânea - RAC, 11(2, Abr/Jun), 11-26.

Miragaia, D. A. M., Ferreira, J., \& Carreira, A. (2014). Do Stakeholders mater in Strategic Decision making of a Sports Organization? RAE - Revista de Administração de Empresas, 54(6), 647-659.

Mitchell, R. K., Agle, B. R., \& Wood, D. J. (1997). Toward a Theory of Stakeholder Identification and Salience : Defining the Principle of Who and What Really Counts. The Academy of Management Review, 22(4), 853-886.

Olander, S. (2007). Stakeholder impact analysis in construction project management. Construction Management and Economics, 25(3), 277-287. http://doi.org/10.1080/01446190600879125

Orth, A. I., \& Prikladnicki, R. (2009). Planejamento e gerência de projetos. Porto Alegre: EDIPUCRS.

Paiva Júnior, F. G. De, Leão, A. L. M. D. S., \& Mello, S. C. B. De. (2011). Validade e confiabilidade na pesquisa qualitativa em administração. Revista de Ciências Da Administração, 13(31), 190-209. http://doi.org/10.5007/2175-8077.2011v13n31p190
Phillips, R., Freeman, R. E., \& Wicks, A. C. (2003). What Stakeholder Theory Is Not. Business Ethics Quaterly, 13(04), 479-502. http://doi.org/10.1017/S1052150X00006710

Premiershiprugby.com,. (2015). Premiership Rugby | Official Site | Aviva Premiership. Retrieved 16 June 2015, from http://www.premiershiprugby.com

Premiershiprugby.com,. (2015). Try Rugby SP Programme. Retrieved 16 June 2015, from http://www.premiershiprugby.com/community/play/try _rugby_sp_programme.php\#jbML7hWtjUgt5uKC.97

Ribeiro, H. C. M. (2014). O Envolvimento da Governança Corporativa, sob a ótica da Toeria dos Stakeholders, na Gestão e no Controle das Entidades Esportivas. Universidade Nove de Julho - UNINOVE.

Ribeiro, M. A. de S. (2012). Modelos De Governança E Organizações Esportivas : Uma Análise Das Federações E Confederações. Escola Brasileira de Administração Pública e de Empresas.

Rugbyready.worldrugby.org,. (2015). Rugby Ready - World Rugby's preparation resource : Retrieved 14 June 2015, from http://rugbyready.worldrugby.org

Senaux, B. (2008). A stakeholder approach to football club governance. International Journal of Sport Management and Marketing, 4(1), 4-17.

SESI. (2015). Caderno Didático de Rugby. São Paulo: SESI-SP Editora.

SESI-SP,. (2014). Relatório de Gestão Anual da Divisão de Esporte e Qualidade de Vida do SESI-SP. 
A Prática da Governança Corporativa e sua Influência Para os Stakeholders Envolvidos no Desenvolvimento de um Projeto Esportivo do Sesi-SP

Shilbury, D., Ferkins, L., \& Smythe, L. (2013). Sport governance encounters: Insights from lived experiences. Sport Management Review, 16(3), 349363. http://doi.org/10.1016/j.smr.2012.12.001

Skaf, P. (2012). Sesi-SP lança programa inédito de rugby para jovens em parceria com British Council e Premiership Rugby.

http://www2.sesisp.org.br/home/2006/news/news.asp?c dgn $=2338$

Sotiriadou, K. (Popi). (2009). The Australian sport system and its stakeholders: development of cooperative relationships. Sport in Society, 12(7), 842860. http://doi.org/10.1080/17430430903053067

Souza, F. C. De, Murcia, F. D.-R., \& Marcon, R. (2011). Bonding Hypothesis : Análise da Relação Entre Disclosure, Governança Corporativa e Internacionalização de Companhias Abertas no Brasil. Contabilidade, Gestão E Governança, 14(2), 62-81.

SP, S. (2015). Serviço Social da Indústria SESISP. Sesisp.org.br. Retrieved 14 June 2015, from http://www.sesisp.org.br

Weitzner, D., \& Peridis, T. (2011). Corporate Governance as Part of the Strategic Process: Rethinking the Role of the Board. Journal of Business Ethics, 102, 33-42. http://doi.org/10.1007/s10551-0111195-0 